\title{
Pollination genetics of the common milkweed, Asclepias syriaca L.
}

\author{
JOEL S. SHORE \\ Department of Biology, York University, 4700 Keele St., North York, Ontario, Canada
}

\begin{abstract}
Electrophoretic methods are used to determine the genotype of individual pollinia simultaneously at several isozyme loci for the common milkweed, Asclepias syriaca. Isozymes of pollinia are the result of gene expression in pollen. Genotype frequencies of maternal plants, pollinia carried by honey bees and pollinia captured by flowers were determined and found to be comparable. Over $50 \%$ of bees carried genotypically mixed pollen loads. Methods for estimating the rate of selfpollination, assuming the mixed-pollination model, are developed and the rate of self-pollination in a population is found to be $66 \%$. The use of the methods developed here for testing various hypotheses, including the operation of sexual selection in plant populations, is discussed.
\end{abstract}

Keywords: Asclepias syriaca L., isozymes, mixed-pollination model, pollinia, self-pollination.

\section{Introduction}

The process of genetic transmission in plants is often mediated by animal pollen vectors. An examination of the role played by pollinators in the pollination process, in addition to post-pollination events (e.g. rejection of self pollen, gametophytic competition, and selective embryo and fruit abortion) is necessary for a complete understanding of the process of genetic transmission. The extent of pollen carryover, the size and genetic composition of pollen loads on pollinators, coupled with pollinator foraging behaviour, are of prime importance in determining the magnitude of gene flow via pollen, as well as the number and genetic relatedness of mates perceived by plants.

The role played by pollinators in genetic transmission has often been inferred from observations of pollinator movements, from the dispersal of naturally or artificially marked pollen (Ganders, 1979; Thomson \& Plowright, 1980; Handel, 1983; Barrett \& Wolfe, 1986) or from genotype frequencies at marker loci in the progeny generation obtained from seeds or seedlings (e.g. Clegg, 1980; Schoen \& Clegg, 1984; Brown et al., 1989; Ellstrand et al., 1989; Ritland, 1989; Broyles \& Wyatt, 1991; Schoen \& Brown, 1991). There may, however, be difficulties associated with the use of these methods as indicators of pollen movement per se. Comparative studies of pollinator movement and gene flow indicate that inferences drawn from the two sources are not necessarily congruent (Schaal,
1980; Levin, 1981; Marshall \& Ellstrand, 1985; Smyth \& Hamrick, 1987; Broyles \& Wyatt, 1991). Dye particles used to mark pollen movement are not necessarily dispersed in the same manner as pollen (Thomson et al., 1986). Naturally and artificially marked pollen usually provide only a limited number of pollen phenotypes (two or three for size heteromorphic pollen found in heterostylous species and species with pollen colour polymorphisms) that can be followed and are thus not particularly informative as relatively few plants in the population can be uniquely marked. Finally, studies of marker genes in the progeny generation may confound pollen transfer with both post-pollination prezygotic events (e.g. gametophytic competition, cryptic self-incompatibility and self-incompatibility responses) and post-zygotic events (e.g. embryo abortion, inbreeding depression and seedling mortality). In this paper, a new method is used to obtain a description of the role played by pollinators in genetic transmission, for the common milkweed, Asclepias syriaca, a self-incompatible species (Kephart, 1981).

The reproductive biology of milkweeds has been the subject of considerable investigation (reviewed in Wyatt \& Broyles, 1990) for several reasons. Its unusual pollination system, found in the Asclepiadaceae and Orchidaceae, allows pollen removal, receipt and presence on pollinators to be readily quantified (e.g. Macior, 1965; Kephart \& Heiser, 1980; Beare \& Perkins, 1982; Morse, 1982; Wolfe, 1987). In the Asclepiadaceae, numerous pollen grains are clustered 
in pollinia which are commonly dispersed in pairs (as pollinaria). To achieve fertilization, a pollinium must be inserted into the stigmatic chamber of a milkweed flower (see Wyatt \& Broyles 1990 for further details). The simultaneous dispersal of an aggregate of pollen from a single flower typically results in shared paternity among all seeds within a fruit (Broyles \& Wyatt, 1990; Gold \& Shore, unpublished data) thus readily enabling the identification of paternal parentage. Finally, the low levels of fruit set relative to flower production have made milkweeds a useful system for investigating processes such as sexual selection, mate choice, selective fruit abortion and other factors that might be responsible for the evolution of inflorescence size (Willson \& Rathcke, 1974; Wyatt, 1976; Willson \& Price, 1977; Wyatt, 1980; Bookman, 1984; Broyles \& Wyatt, 1990).

In this study of $A$. syriaca, it is shown that it is possible to determine the genotype of individual pollinia simultaneously at several isozyme loci. A comparison is made between genotype frequencies of maternal plants, pollinia carried by bees, and pollinia captured by flowers (i.e. pollinia inserted into the stigmatic chamber). In addition, a statistical method to test the hypothesis that high levels of self-pollination occur in this species is developed and used. It has been proposed that high rates of self-pollination are responsible for the low percentage fruit set exhibited by milkweeds (Wyatt, 1980; Wyatt \& Broyles, 1990).

\section{Materials and methods}

In June of 1991, inflorescences (umbels) from 31 widely spaced plants of $A$. syriaca were sampled in an old field adjacent to the York University campus, Ontario, Canada. On three successive days, honey bees, Apis mellifera (the most common floral visitor), that carried at least two pollinaria were collected. Both inflorescences and bees were stored at $-80^{\circ} \mathrm{C}$ until they could be dissected.

All pollinia were removed from each of the 24 bees, for electrophoretic analysis. Successive flowers were dissected from each plant until a total of eight pollinia, which were inserted into the stigmatic chamber of the flowers, were removed for electrophoresis. Either intact pollinaria or single pollinia attached to a corpusculum were assayed. In no instances were pollinia run that were not attached to a corpusculum. This was done to ensure that pollinia from the same pollinarium were not assayed. In addition to pollinia that were inserted into the stigmatic chamber by pollinators, pollinia produced by each inflorescence were assayed to obtain the genotype of the maternal plant and hence the frequency of maternal genotypes in the population.

\section{Electrophoresis}

Starch gel electrophoresis of enzymes was carried out with modifications of the methods used by Shore \& Barrett (1987). Individual pollinia or pollinaria were crushed in 7-14 $\mu \mathrm{l}$ of a $0.05 \mathrm{M} \mathrm{Na}_{2} \mathrm{HPO}_{4}$ buffer $(\mathrm{pH}=7)$ containing $1 \mathrm{mg} \mathrm{ml}^{-1}$ of dithiothreitol. Narrow filter paper wicks (approximately $1.5 \mathrm{~mm} \times 8$ mm Whatman 1) were used to absorb the extracts. Individual pollinia were assayed electrophoretically for the following enzymes: aconitase (Aco), alcohol dehydrogenase $(A d h)$, glutamate dehydrogenase $(G d h)$, glutamate oxaloacetate transaminase (Got), isocitric dehydrogenase $(I d h)$, malate dehydrogenase $(M d h)$, menadione reductase $(M n r)$, 6-phosphogluconate dehydrogenase $(P g d)$, phosphoglucose isomerase $(P g i)$, phosphoglucomutase (Pgm) and shikimate dehydrogenase $(S k d)$. Assays followed those cited in Shore \& Barrett (1987) and Shore (1991) with the exception of the assay for $M n r$ which was obtained from Wendel \& Weeden (1989). Petals of maternal plants were also assayed to determine whether a particular isozyme was the result of gene expression in pollen or in the sporophytic structural tissue that also occurs in the pollinia.

\section{Statistical analyses}

The rate of self-pollination was estimated for each locus as well as for all loci combined (multilocus estimate) using a modification of the procedure for estimating the mixed mating system (Clegg, 1980). Assumptions analogous to those of the mixed mating model apply here including the following: (i) captured pollinia are derived from two sources, (a) from the same plant (self-pollination) or (b) a random sample from the outcross pollinia pool; (ii) the pollinia pool is homogeneous across maternal plants; and (iii) the probability of outcrossed pollination is constant for all maternal plants. The estimation procedure differs in two ways: (i) diploid genotypes of pollinia in the pollinia pool are estimated (rather than allele frequencies in the pollen pool); and (ii) the rate of self-pollination (rather than self-fertilization) is estimated.

The probabilities of observing various pollinia genotypes given the maternal genotype (assuming the mixed pollination model above) for the case where there are three maternal and pollinia genotypes in the population are provided in Table 1 . The procedure may be extended to any number of genotypes at single or multiple loci. In general, for a diploid maternal genotype, $i$, the expected proportion of pollinia captured that are of diploid genotype, $j$, is given by, $s+t \times P_{j}$, when $i=j$ (i.e. when maternal plant and the captured pollinium have the same genotype), and $t \times P_{j}$, 
Table 1 Conditional distributions of pollinia inserted into the stigmatic chamber given maternal genotype and assuming the mixed pollination model. $p, q$, and $r$ are the frequencies of the pollinia genotypes $A_{1} A_{1}, A_{1} A_{2}$ and $A_{2} A_{2}$, respectively, in the pollinia pool $(p+q+r=1)$ and $s$ and $t$ are the rates of self- and outcrossed pollination $(s+t=1)$

\begin{tabular}{llll}
\hline & \multicolumn{2}{l}{ Pollinia genotype } \\
\cline { 2 - 4 } Maternal genotype & $\mathrm{A}_{1} \mathrm{~A}_{1}$ & $\mathrm{~A}_{1} \mathrm{~A}_{2}$ & $\mathrm{~A}_{2} \mathrm{~A}_{2}$ \\
\hline $\mathrm{A}_{1} \mathrm{~A}_{1}$ & $s+t p$ & $t q$ & $t r$ \\
$\mathrm{~A}_{1} \mathrm{~A}_{2}$ & $t p$ & $s+t q$ & $t r$ \\
$\mathrm{~A}_{2} \mathrm{~A}_{2}$ & $t p$ & $t q$ & $s+t r$ \\
\hline
\end{tabular}

for all other instances, where $s$ and $t(s+t=1)$ are the rates of self- and outcross-pollination, respectively. The genotypes $i$ and $j$ may be single or multilocus genotypes. $P_{j}$ are pollinia genotype frequencies.

Maximum likelihood estimates of the pollination parameters (pollinia genotype frequencies and selfpollination rates) were obtained using a general maximum likelihood estimation program (Reed \& Schull, 1968; Manly, 1985). It should be noted, however, that estimates can be obtained directly when only two genotypes occur in the population sample (see Appendix). Separate versions of the program were written to obtain estimates when different numbers of genotypes occurred at a locus in the population samples. The program performs numerical differentiation and finds the maximum likelihood estimates using NewtonRaphson iteration. It was necessary to write a subroutine for the program that specified the probability of observing various pollinia genotypes as a function of the set of parameters to be estimated.

In principle, multilocus maximum likelihood estimates of the rate of self-pollination can be obtained numerically, as above. For the present data, however, a large number of multilocus genotypes would need to be estimated, making it unwieldy to write a program subroutine to obtain the estimates, so an alternative approach was used. A multilocus estimate of the rate of self-pollination was obtained using a modification of the multilocus mating system estimation procedure of Shaw et al. (1981). Again, the modification involved estimation of diploid genotypes rather than allele frequencies. In essence, the procedure allows an estimate of the frequency of cryptic outcross pollinations (i.e. instances where outcross pollinia and the maternal plant have the same genotype at the marker loci) to be made. The multilocus probability of non-identification of outcross pollination is given by,

$$
\prod_{k=1}^{m}\left[\sum_{i j=1}^{g} M_{k i} \times P_{k j}\right],
$$

for $i=j$ over $g$ genotypes and $m$ loci. $M_{k i}$ and $P_{k j}$ are maternal and pollinia genotype frequencies. This gives an estimate of a value analogous to $\alpha$ in Shaw et al. (1981) and the multilocus outcross pollination rate and its standard error are then obtained directly as in Shaw et al. (1981).

Heterogeneity $\chi^{2}$ tests comparing genotype frequencies as well as single locus self-pollination rates were carried out following Bailey (1961).

\section{Results}

\section{Electrophoresis}

Highly active enzymes were obtained from single pollinia (Fig. 1). It was possible to load extracts of single pollinia onto two gels and assay up to 10 different enzymes for each pollinium. In addition to the polymorphic loci scored here, good enzyme activity was obtained for Aco and Idh, both of which were monomorphic in the population. Very weak activity was observed for Got and $S k d$, neither of which could be reliably scored. No enzyme activity was observed for $G d h$. In some instances, no activity was detected for individual pollinia; this might have been due to excessive age as it was found that pollinia for which pollen had begun to germinate often yielded less intense staining activity. A total of 248 pollinia captured by flowers was assayed and 240 yielded adequate enzyme activity.

As pollinia are composed of an aggregate of haploid pollen as well as diploid sporophytic tissue, it is possible that the enzyme activity detected is due to enzymes from one or both tissues. To determine whether the isozymes resulted from gene expression in pollen, sporophytic tissue, or both, pollinia produced by a flower as well as diploid petal tissue of that flower were assayed. Ten plants known to be heterozygous for at least one locus for a dimeric enzyme as well as homozygotes were assayed. If enzyme activity is the result of gene expression in the pollen alone, then heterozygotes should exhibit two bands, as opposed to three, for the diploid petal tissue (following Weeden \& Gottlieb, 1979). Heterozygotes and homozygotes were assayed for the four polymorphic dimeric enzymes examined in this study: Adh-1, Mdh-1, Pgd-1 and Pgi-2. All showed three bands when floral tissue was assayed 
but only two when pollinia were assayed. A photograph comparing banding patterns of pollinia with petal tissue for Pgd-1 is presented in Fig. 1. The results indicate that the enzyme activity detected is the result of gene expression in pollen.

Adh-1, Mdh-1, Mnr-1, Pgd-1, Pgi-2 and Pgm-1 were polymorphic in the population although only two of these loci (Mnr-1 and Pgm-1) possessed alleles at moderate frequencies. An additional locus was poly-

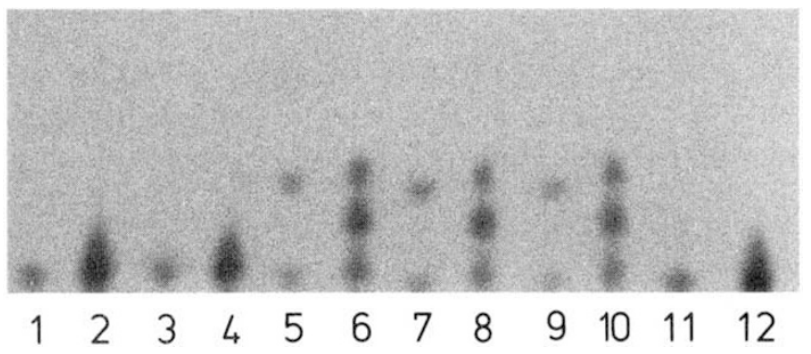

Fig. 1 Photograph of an isozyme gel for the $P g d-1$ locus. Odd-numbered lanes represent pollinia extracts while adjacent even-numbered lanes represent extracts of petal tissue obtained from the same flower as the adjacent pollinium. Lanes 1-4 and 11-12 are slow homozygotes (ss). Lanes 5-10 are heterozygotes $(f s)$. Note that lanes 6, 8, 10 from petal tissue show typical 3-banded heterozygous patterns while the corresponding pollinia lanes $(5,7,9)$ show 2-banded patterns as expected if the isozyme is the result of gene expression in pollen. morphic $(P g d-2)$ but was often faint and could not be reliably scored. The frequencies of genotypes were determined for maternal plants, for pollinia carried by bees, as well as for the estimated outcross pollinia pool captured by flowers (Table 2). A heterogeneity $\chi^{2}$ test for each locus, using the frequency of the most common genotype at each locus, revealed marginally significant heterogeneity in only one instance (Table 2). Overall, the results indicate that genotype frequencies are comparable among maternal plants, pollinia carried by pollinators and the estimated outcross pollinia pool. Considering all loci simultaneously, 24 different six-locus genotypes were observed among pollinia captured by flowers, 15 occurred on pollinators and 11 different six-locus genotypes were observed among the maternal plants.

Twenty-four bees were captured that possessed at least two pollinia and one bee had the maximum of 12 pollinia. A total of 124 pollinia obtained from bees were assayed. The distribution of the number of pollinia carried by bees is positively skewed (Fig. 2). For all six bees carrying only two pollinia, members of a pair could not be distinguished genotypically at any of the six polymorphic isozyme loci (Fig. 2). Two bees each possessed five pollinia that could not be distinguished. For bees carrying six or more pollinia, at least two genotypes could always be detected. One bee carrying 10 pollinia had six genotypically distinguishable pollinia. Over half of the bees examined (13 of 24)

Table 2 Genotype frequencies and standard errors (s.e.) for maternal plants, pollinia on pollinators and the pollinia pool estimated from the pollination system. Heterogeneity $\chi^{2}$ statistics are provided to test for heterogeneity among the genotype frequencies for the most common genotype at each locus

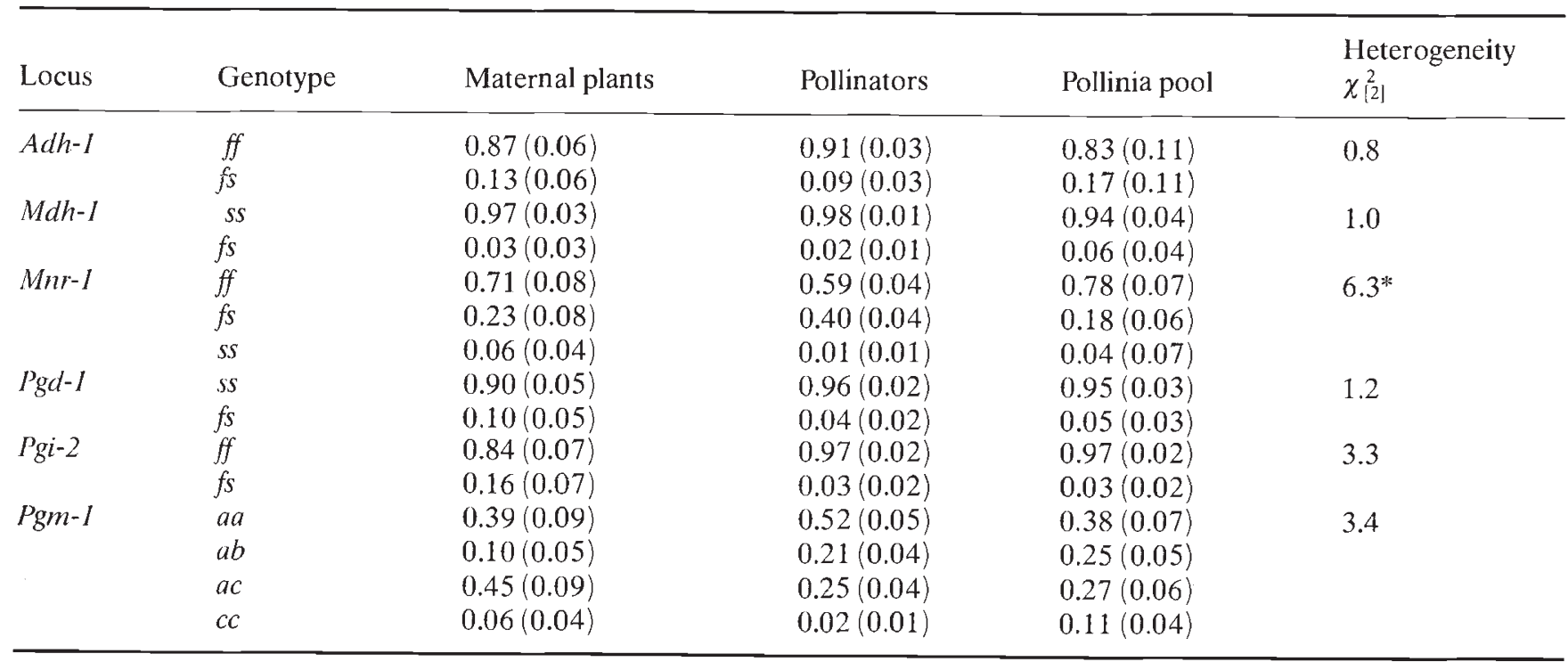

$* P<0.05$. 
were carrying pollinia obtained from two or more genotypically distinguishable plants. One quarter of bees carried pollinia derived from three or more plants.

To test the hypothesis that fruit production in $A$. syriaca is pollen limited, as a result of high rates of selfpollination and perhaps concomitant stigmatic clogging, the rate of self-pollination was estimated (Table $3)$. For the six polymorphic loci, self-pollination rates ranged from 58 per cent to 88 per cent with a mean of 69 per cent, close to the multilocus estimate of 66 per cent. There was significant heterogeneity among the single locus estimates (Table 3 ). In the two instances where sufficient degrees of freedom were available for a goodness of fit test (for $M n r-1$ and Pgm-1), the data fit the mixed pollination model (Table 3). A comparison of multilocus maternal and captured pollinia genotypes revealed that 75 of 240 ( 31 per cent) of captured pollinia were the result of directly observable outcross pollinations. This would give a self-pollination rate of 69 per cent if identical genotypes are the result of selfpollination. This value is expected to be larger than the multilocus self-pollination estimate as it does not compensate for cryptic outcross pollinations. Over all loci, relatively high rates of self pollination occur in this population.

\section{Discussion}

The ability to determine the genotype of individual pollinia simultaneously at numerous isozyme loci in $A$. syriaca and possibly other Asclepiadaceae may extend the usefullness of these species for addressing hypotheses concerning the evolution of inflorescence size and the operation of processes such as sexual selection, selective fruit abortion and mate choice. Using the methods presented here, it should be possible to assess the pollen exported by individual males, transported by pollinators, and subsequently captured by females. Finally, the success of plants as males may be determined by assaying the progeny generation (following Broyles \& Wyatt, 1990).

An estimate of the rate of self-pollination (as opposed to self-fertilization) in a population of $A$. syriaca was obtained and found to be approximately 66 per cent. This result is consistent with the hypothesis that low fruit set in $A$. syriaca is the result of insufficient compatible pollination, as was observed by Morse \& Fritz (1983), and/or stigmatic clogging, but by no means proves that this is the case.

High rates of self-pollination in this species may be, in part, the result of geitonogamous pollination resulting from pollinia transfer among flowers within and between umbels on a single plant as well as among ramets within a clone. This species is known to reproduce extensively by vegetative means (Kephart et al.,

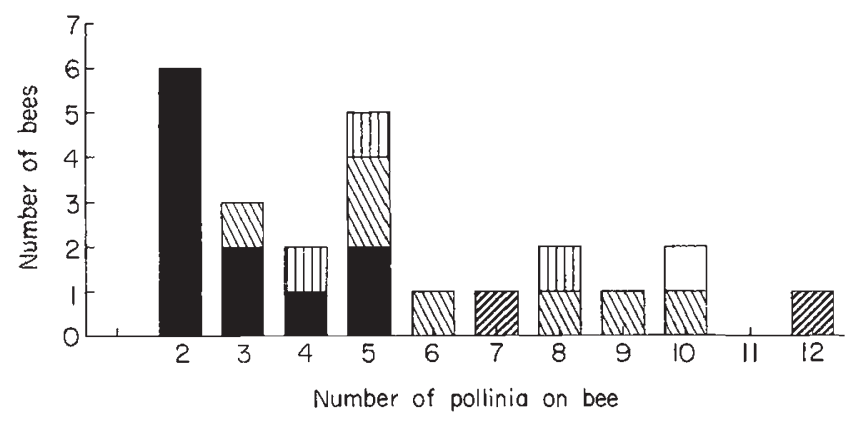

Fig. 2 Frequency distribution of numbers of bees carrying various numbers of pollinia. The number of different genotypes detected on each bee is also indicated. ( 1 Genotype, $(\mathbb{*}) 2$ genotypes, (m) 3 genotypes, ( 4 ) 4 genotypes, $(\square) 6$ genotypes.

Table 3 Maximum likelihood estimates of single and multilocus rates of selfpollination, $s$, and their standard errors (s.e.). Number of maternal and pollinia genotypes used for estimation for each locus is indicated. Goodness of fit tests are applied when degrees of freedom (d.f.) are available

\begin{tabular}{llllll}
\hline Isozyme locus & Number of genotypes & $s(s . e)$. & $\chi^{2}$ & d.f. & $p$ \\
\hline Adh-1 & 2 & $0.88(0.05)$ & - & 0 & - \\
Mdh-1 & 2 & $0.60(0.17)$ & - & 0 & - \\
Mnr-1 & 3 & $0.73(0.05)$ & 4.93 & 3 & 0.18 \\
Pgd-1 & 2 & $0.58(0.11)$ & - & 0 & - \\
Pgi-2 & 2 & $0.68(0.08)$ & - & 0 & - \\
Pgm-1 & 4 & $0.65(0.04)$ & 4.79 & 8 & 0.78 \\
Mean single locus $s$ & & $0.69(0.11)$ & $14.19^{*}$ & 5 & 0.01 \\
Multilocus $s$ & & $0.66(0.03)$ & & & \\
\hline
\end{tabular}

*Heterogeneity $\chi^{2}$. 
1988). While the degree of self-pollination in other populations would need to be estimated before general conclusions about the species can be made, it is likely that the amount of clonal reproduction in a particular population will be an important determinant of the extent of self-pollination. Pleasants (1991), using radioactively labelled pollinia, estimated the extent of within umbel pollination in $A$. syriaca to be 37 per cent which would suggest that the self-pollination rate is at least 37 per cent. Furthermore, he estimated that 71 per cent of labelled pollinia were inserted geitonogamously or within $1 \mathrm{~m}$ of the labelled source plant indicating that the extent of self-pollination is likely to be much larger than 37 per cent.

At least one half of the bees investigated carried genotypically mixed loads of pollinia, therefore pollinators are likely to increase pollen flow and the number of mates perceived by maternal plants through pollen carryover. Perhaps even greater levels of self-pollination would occur in the absence of these mixed pollinia loads in this clonal species.

It should be possible to extend the methods used here to other pollinia-bearing species (in the Asclepiadaceae and Orchidaceae), and perhaps to species that disperse pollen in smaller aggregates. Pollen is shed in multiple units in 55 plant families including pollen shed as dyads, tetrads or larger aggregates (Kress, 1981). For example, some species in the Ericaceae and Onagraceae shed pollen in large aggregates held together by viscin threads.

Mulcahy et al. (1981) and Gay et al. (1986), have successfully performed gel electrophoresis on single pollen grains from species of Cucurbita. Hence, it may even be possible to extend the approach to species that shed pollen as single grains. The small size of individual grains would, however, make their individual removal from pollinators and stigmas difficult. It is also unlikely that a large number of enzymes could be assayed from a single grain, although methods for assaying small amounts of tissue are available (Kazmer, 1991). Single haploid pollen grains will not be as informative as an aggregation of pollen because complete information on the diploid paternal genotype will not be available from haploid pollen. It may be possible that the use of random amplified polymorphic DNA (Williams et al., 1990) will further enable the discovery of additional loci that can be visualized with small quantities of DNA found in pollen.

The methods presented here, combined with detailed demographic studies of pollinia, such as those by Morse (1982), will allow information on the demographic genetics of the male gametophytic life-history stage to be obtained. This will provide information on a life-history stage that, previously, was not readily amenable to analysis.

\section{Acknowledgements}

I would like to thank Angela Baker, Mark DeBoer, Erika Hansell and especially Gus Lagos for technical assistance, and Laurence Packer and Helen Rodd for comments on the manuscript. The study was funded by a Natural Sciences and Engineering Research Council operating grant to J. S. Shore.

\section{References}

BAILEY, N. T. J. (1961). Mathematical Theory of Genetic Linkage. Oxford University Press, London.

BARRETT, S. C. H. AND WOLFE, L. M. 1986. Pollen heteromorphism as a tool in studies of the pollination process in Pontederia cordata L. In: Mulcahy, D. L., Bergamini Mulcahy, G. and Ottaviano, E. (eds) Biotechnology and Ecology of Pollen. Springer-Verlag, New York, pp. 435-442.

BEARE, M. H. AND PERKINS, W. E. 1982. Effects of variation in floral morphology on pollination mechanisms in Asclepias tuberosa L., butterflyweed (Asclepiadaceae). Am. J. Bot., 69, 579-584.

BOOKMAN, s. s. 1984. Evidence for selective fruit production in Asclepias. Evolution, 38, 72-86.

BRoWn, A. H. D., BURdon, J. J. AND JARosz, A. M. 1989. Isozyme analysis of plant mating systems. In: Soltis, D. E. and Soltis, P. S. (eds) Isozymes in Plant Biology. Dioscorides Press, Portland Oregon, pp. 73-86.

BROWN, A. H. D., MATHESON, A. C. AND ElDRIDGE, K. G. 1975. Estimation of the mating system of Eucalyptus obliqua L'Herit by using allozyme polymorphisms. Australian J. Bot., 25, 931-949.

BROYLES, S. B. AND WYATT, R. 1990. Paternity analysis in a natural population of Asclepias exaltata: multiple paternity, functional gender, and the 'pollen donation hypothesis'. Evolution, 44, 1454-1468.

BROYLES, S. B. AND WYATT, R. 1991. Effective pollen dispersal in a natural population of Asclepias exaltata: the influence of pollinator behavior, genetic similarity, and mating success. Am. Nat., 138, 1239-1249.

ClEGG, M. T. 1980. Measuring plant mating systems. Bioscience, 30, 814-818.

Ellstrand, N. C., DEVlin, B. AND MARShall, D. L. 1989. Gene flow by pollen into small populations: data from experimental and natural stands of wild radish. Proc. Natl. Acad. Sci. USA, 86, 9044-9047.

GANDERS, F. R. 1979. The biology of heterostyly. New Zealand J. Bot., 17, 607-635.

GAY, G., KERHOAS, C. AND DUMAS, C. 1986. Micro-isoelectric focusing of pollen grain proteins in Cucurbita pepo, L. In: Mulcahy, D. L., Bergamini Mulcahy, G. and Ottaviano, E. (eds) Biotechnology and Ecology of Pollen. SpringerVerlag, New York, pp. 496-498.

HANDEL, S. N. 1983. Pollination ecology, plant population structure, and gene flow. In: Real, L. (ed) Pollination Biology. Academic Press, New York, pp. 163-211. 
KAZMER, D. J. 1991. Isoelectric focusing procedures for the analysis of allozymic variation in minute arthropods. Ann Entomol. Soc. Am., 84, 332-339.

KEPHART, S. R. 1981. Breeding systems in Asclepias incarnata L., A. syriaca L., and A. verticillata L. Am. J. Bot., 68 , 226-232.

KEPHART, S. R. AND HEISER, C. B. JR. 1980. Reproductive isolation in Asclepias: lock and key hypothesis reconsidered. Evolution, 34, 738-746.

KEPHART, S. R., WYATT, R. AND PARRELLA, D. 1988. Hybridization in North American Asclepias. I. Morphological evidence. Syst. Bot., 13, 456-473.

KRESS, W. J. 1981. Sibling competition and evolution of pollen unit, ovule number, and pollen vector in angiosperms. Syst. Bot., 6, 101-112.

LEvin, D. A. 1981. Dispersal versus gene flow in plants. Ann. Miss. Bot. Garden, 68, 233-253.

MACIOR, L. W. 1965. Insect adaptation and behavior in Asclepias pollination. Bull. Torrey Bot. Club, 92, 114126.

MARSHALL, D. L. AND ELLSTRAND, N. C. 1985. Proximal causes of multiple paternity in wild radish, Raphanus sativus. Am. Nat., 126, 596-605.

MANLY, B. F. J. 1985. The Statistics of Natural Selection. Chapman and Hall, New York.

MORSE, D. H. 1982. The turnover of milkweed pollinia on bumble bees, and implications for outcrossing. Oecologia, 53, 187-196.

MORSE, D. H. AND FRITZ, R. S. 1983. Contributions of diurnal and nocturnal insects to the pollination of common milkweed (Asclepias syriaca L.) in a pollen-limited system. Oecologia, 60, 190-197.

MULCAHY, D. L., ROBINSON, R. W., IHARA, M. AND KESSELI, R. 1981. Gametophytic transcription for acid phosphatases in pollen of Cucurbita species hybrids. J. Hered., 72, 353-354.

PLEASANTS, J. M. 1991. Evidence for short-distance dispersal of pollinia in Asclepias syriaca L. Funct. Ecol., 5, 75-82.

PEAKALL, R. 1989. A new technique for monitoring pollen flow in orchids. Oecologia, 79, 361-365.

PLEASANTS, J. M., HORNER, H. T. AND NG, G. 1990. A labelling technique to track dispersal of milkweed pollinia. Funct. Ecol., 4, 823-827.

REED, T. E. AND SCHULL, w. J. 1968. A general maximum likelihood estimation program. Am. J. Hum. Genet., 20, 579-580.

RITLAND, K. 1989. Correlated matings in the partial selfer Mimulus guttatus. Evolution, 43, 848-859.

SCHAAL, B. A. 1980. Measurement of gene flow in Lupinus texensis, Nature, 284, 450-451.

SCHOEN, D. J. AND BROWN, A. H. D. 1991. Whole- and part-flower self-pollination in Glycine clandestina and $G$. argyrea and the evolution of autogamy. Evolution, 45, 1651-1664.

SCHOEN, D. J. AND CLEGG, M. T. 1984. Estimation of mating system parameters when outcrossing events are correlated. Proc. Natl. Acad. Sci. USA, 81, 5258-5262.

SHAW, D. V., KAHLER, A. L. AND ALLARD, R. W. 1981. A multilocus estimator of mating system parameters in plant populations. Proc. Natl. Acad. Sci. USA , 78, 1298-1302.
SHORE, J. S. 1991. Tetrasomic inheritance and isozyme variation in Turnera ulmifolia vars. elegans Urb. and intermedia Urb. (Turneraceae). Heredity, 66, 305-312.

SHORE, J. S. AND BARRETT, S. C. H. 1987. Inheritance of floral and isozyme polymorphisms in Turnera ulmifolia L. J. Hered., 78, 44-48.

SMYTH, C. A. AND HAMRICK, J. L. 1987. Realized gene flow via pollen in artificial populations of musk thistle, Carduus nutans L. Evolution, 41, 613-619.

THOMSON, J. D. AND PLOWRIGHT, R. C. 1980. Pollen carryover, nectar rewards, and pollinator behavior with special reference to Diervilla lonicera. Oecologia, 46, 68-74.

THOMSON, J. D., PRICE, M. V., WASER, N. M. AND STRATTON, D. A. 1986. Comparative studies of pollen and fluorescent dye transport of bumble bees visiting Erythronium grandiflorum. Oecologia, 69, 561-566.

WEEDEN, N. F. AND GotTlleB, L. D. 1979. Distinguishing allozymes and isozymes of phosphoglucoseisomerases by electrophoretic comparisons of pollen and somatic tissues. Biochem. Genet., 17, 287-296.

WENDEL, J. F. AND WEEDEN, N. F. 1989. Visualization and interpretation of plant isozymes. In: Soltis, D. E. and Soltis, P. S. (eds) Isozymes in Plant Biology. Dioscorides Press, Portland Oregon, pp. 5-45.

WILLIAMS, J. G. K., KUBELIK, A. R., LIVAK, K. J., RAFALSKI, J. A. AND TINGEY, S. V. 1990. DNA polymorphisms amplified by arbitrary primers are useful as genetic markers. Nucl. Acids Res., 18, 6531-6535.

WILLSON, M. F. AND RATHCKE, B. J. 1974. Adaptive design of the floral display in Asclepias syriaca L. Am. Midland Natural., 92, 47-57.

WILLSON, M. F. AND PRICE, P. W. 1977. The evolution of inflorescence size in Asclepias (Asclepiadaceae). Evolution, 31, 495-511.

WOLFE, L. M. 1987. Inflorescence size and pollinaria removal in Asclepias curassavica and Epidendrum radicans. Biotropica, 19, 86-89.

WYATT. R. 1976. Pollination and fruit-set in Asclepias: a reappraisal. Am. J. Bot., 63, 845-851.

WYATT, R. 1980 . The reproductive biology of Asclepias tuberosa: I. Flower number, arrangement, and fruit-set. New Phytol., 85, 119-131.

WYATT, R. AND BROYLES, S. B. 1990. Reproductive biology of milkweeds. (Asclepias): recent advances. In: Kawano, S. (ed) Biological Approaches and Evolutionary Trends in Plants. Academic Press, Toronto, pp. 255-272.

\section{Appendix}

For loci where only two genotypes occur (e.g. $A_{1} A_{1}$ and $A_{1} A_{2}$ ) in the population sample (e.g. for a diallelic locus where allele frequencies are highly asymmetrical), the number of degrees of freedom is equal to the number of independent parameters to be estimated and hence, it is possible to find the maximum likelihood estimates and standard errors directly, using methods detailed in Brown et al. 
(1975). (This situation is exactly analogous to case (i), Appendix I, in Brown et al. 1975.) Let the observed numbers of pollinia of genotypes $A_{1} A_{1}$ and $A_{1} A_{2}$ from maternal genotype $A_{1} A_{1}$ be $O_{1}$ and $O_{2}$, respectively, and the total number of pollinia assayed from maternal genotype $A_{1} A_{1}$ be $N_{11}$. Similarly, let the observed numbers of pollinia of genotypes $A_{1} A_{1}$ and $A_{1} A_{2}$ be $\mathrm{O}_{3}$ and $\mathrm{O}_{4}$, respectively, and the total number of pollinia assayed from maternal genotype $A_{1} A_{2}$ be $N_{12}$. The rate of self-pollination and its standard error are obtained as follows: $\hat{s}=\mathrm{O}_{1} / \mathrm{N}_{11}-\mathrm{O}_{3} / \mathrm{N}_{12}$ and the standard error is given by $\left(\mathrm{O}_{1} \times \mathrm{O}_{2} /\left(\mathrm{N}_{11}\right)^{3}+\mathrm{O}_{3} \times \mathrm{O}_{4} /\right.$ $\left.\left(\mathrm{N}_{12}\right)^{3}\right)^{1 / 2}$. If $p$ is the frequency of the genotype $A_{1} A_{1}$ in the pollinia pool then $p$ and its standard error are obtained as: $\hat{p}=\mathrm{O}_{3} / \mathrm{N}_{12} /(1-\hat{s})$ and the standard error is

$$
\left(\frac{\frac{\mathrm{O}_{2}^{2} \times \mathrm{O}_{3} \times \mathrm{O}_{4}}{\left(\mathrm{~N}_{11}\right)^{2} \times\left(\mathrm{N}_{12}\right)^{3}}+\frac{\mathrm{O}_{1} \times \mathrm{O}_{2} \times \mathrm{O}_{3}^{2}}{\left(\mathrm{~N}_{12}\right)^{2} \times\left(\mathrm{N}_{11}\right)^{3}}}{(1-\hat{s})^{4}}\right)^{1 / 2} \text {. }
$$

The outcrossed pollination rate $(t)$ and the alternative genotype frequency $(q)$ may be estimated as follows: $\hat{t}=1-\hat{s}$ and $\hat{q}=1-\hat{p}$. 